\title{
Sodium vitamin C transporter 2 orchestrates lactate metabolism in mouse Sertoli cells
}

\author{
Guozheng Gao1,*, Yong Zhao2,*, Ke Wang ${ }^{2}$ and Fang Wang1 \\ ${ }^{1}$ Center of Reproductive Medicine, Luoyang Central Hospital Affiliated to Zhengzhou University, Luoyang City, Henan Province, People's Republic of China \\ ${ }^{2}$ Center of Assisted Reproductive Medicine, The Sixth Medical Center of PLA General Hospital, Beijing, People's Republic of China
}

Correspondence should be addressed to F Wang: wangfang_1967@sina.com

*(G Gao and Y Zhao contributed equally to this work)

\begin{abstract}
Transportation of vitamin C (also called ascorbic acid (AA)), an important watersoluble antioxidant and cofactor in testis, requires glucose transporter family (GLUTs) and sodium/vitamin C cotransporter family (SVCT1 and SVCT2). There is so far scant information vis-à-vis the functional roles of SVCTs in testis, although they possess higher affinity for transportation of AA compared to GLUTs. To analyze the biological effects of SVCT2 in testis, we assessed testicular expression of SVCT2 in different experimental settings and the effect of SVCT2 ablation on spermatogenesis. Persistent expression of SVCT2 was shown in the mouse testis at different stages of postnatal development, demonstrated on day 14 of testicular development in mice consistent with the appearance of pachytene spermatocytes during the first wave of spermatogenesis. Testicular expression of SVCT2 was enriched in the cytoplasm of murine Sertoli cells (SCs). We then showed that in vivo inhibition of SVCT2 in mouse testis significantly impaired male fertility by causing oligozoospermia and asthenospermia, which mainly stemmed from a deficiency in lactate production. By generating the TM4SVCT2-I- cells and by profiling TM4SVCT2-/- cells with a constitutively activated HIF-1 $\alpha$ mutant, we demonstrated that SVCT2 deficiency led to impaired lactate synthesis and reduced expression of Ldha mRNA in SCs. Mechanistically, ablation of SVCT2 resulted in ubiquitination and subsequent degradation of HIF-1 $\alpha$ protein in the FSH-stimulated SCs. Collectively, our data document a novel testicular site of action of SVCT2 in the control of lactate synthesis by SCS, probably via ubiquitination-dependent regulation of HIF-1 $\alpha$ stability.
\end{abstract}

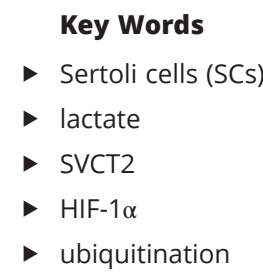

Journal of Molecular Endocrinology (2021) 66, 157-170

\section{Introduction}

Vitamin C (also called ascorbic acid/AA), acting as a major antioxidant inside testis (Angulo et al. 2011), is such a striking example. In guinea pig, it has been shown that the deficient diet causes massive degeneration of the seminiferous epithelium (Angulo et al. 2008). Using in vitro approaches, Dawson et al. have revealed that agglutination of normal spermatozoa occurs in the absence of vitamin $\mathrm{C}$ can be reversed by supplement with exogenous vitamin C (Dawson et al. 1992). Therefore, vitamin $C$ is an essential micronutrient required for normal spermatogenesis. Transportation of vitamin $\mathrm{C}$ inside cells is dependent on two transport systems, namely glucose transporter family (GLUT1-GLUT14) and sodium/ vitamin C cotransporter family (SVCT1 and SVCT2). 
As compared to the low-affinity, high-capacity sodiumindependent GLUTs, SVCTs exhibit a high specificity profile for reduced vitamin $\mathrm{C}$ and transport AA down the electrochemical sodium gradient (Liang et al. 2001). Both SVCT1 and SVCT2 have been shown to be expressed in testis (Angulo et al. 2011). From a functional standpoint, SVCT1 is involved in whole-body homeostasis of vitamin C, while SVCT2 protects metabolically active cells against oxidative stress. More importantly, only SVCT2 is reported to be functionally linked to concerted glucose transport inhibition and lactate transport stimulation in nonneuronal cells (Castro et al. 2008). To this end, it is tempting to hypothesize that SVCT2 may play a more important role in energy metabolism in Sertoli cells (SCs). Nonetheless, the functional details and corresponding molecular basis of testicular SVCT2 remain largely unknown.

During mammalian spermatogenesis, development and differentiation of meiotic spermatocytes and postmeiotic spermatids are solely dependent on the lactate produced by adjacent SCs, due to the fact that several enzymes in the glycolytic pathway are spermatogenic cellspecific (e.g. hexokinase, phosphoglycerate kinase-2 and glyceraldehyde 3-phosphate dehydrogenase) (Boussouar \& Benahmed 2004). In fact, it has been recognized for nearly 20 years that SCs convert glucose to lactate to influence the survival of germ cells (GCs) (Boussouar \& Benahmed 2004). Previous evidence has shown that disruption of lactate production by SCs contributes essentially to male infertility by causing defects or developmental arrest in germ cells (GCs) of specific cellular type (Jain \& Halder 2012). In addition, during the last decades, it has become more apparent that oxidative stress, induced by high rates of cell division and mitochondrial oxygen consumption during spermatogenesis, are involved in the auto-/paracrine control of lactate metabolism and Sertoligerm cell interaction under various pathophysiological conditions (Aitken \& Roman 2008, Li et al. 2015, Dong et al. 2017, Shen et al. 2018, Sun et al. 2019, Jin et al. 2020, Uriostegui-Acosta et al. 2020). In this regard, emerging results have been recently reported for the testicular expression and/or direct biological actions of an array of oxidative stress-related factors with potent roles in modulating lactate metabolism, such as prostaglandin D2 (Rossi et al. 2016), GATA4 (Schrade et al. 2016) and nuclear factor (erythroid-derived 2)-like 2 (NRF2) (Regueira et al. 2015). Conceivably, these results together leave the open possibility that energy balance and redox homeostasis might be jointly regulated in testis, and clearly point out the functional diversity of a number of novel molecules whose biological functions largely exceed nutritional supply and redox metabolism.

Because of the presence of sodium-dependent vitamin C transporters, AA is highly concentrated in brain, testis and adrenal glands (Castro et al. 2008). More importantly, AA has been shown to participate in a general mechanism for concerted glucose transport inhibition and lactate transport stimulation in both neuronal and non-neuronal cells (Castro et al. 2009). These reports thus raise the possibility that the factors mediating the vitamin $\mathrm{C}$ signaling might regulate lactate metabolism in certain cell types (e.g. SCs and GCs).

On the aforementioned basis, we sought: (1) to determine the expression profile of SVCT2 in mouse testis, (2) to illustrate any biological effects upon ablation of endogenous SVCT2 expression, and (3) to elucidate the potential mechanisms which might underlie the SVCT2 action in distinct testicular cell types. Overall, our systematic analysis should pave the way for a better understanding of the SVCT2 function during complicated spermatogenesis.

\section{Materials and methods}

\section{Animal model}

C57BL/6J male mice bred in the animal facility of Luoyang Central Hospital Affiliated to Zhengzhou University were used. Mice were maintained under a constant $12 \mathrm{~h}$ light: $12 \mathrm{~h}$ darkness cycle (lights on at 08:00 h), and controlled conditions of humidity (between 70 and $80 \%)$ and temperature $\left(22 \pm 1^{\circ} \mathrm{C}\right)$, with free access to tap water and standard pellet chow. Mice were allowed to acclimatize for 7 days before experiments. To achieve the in vivo inhibition of SVCT2 expression, mice were injected intraperitoneally (i.p.) with SVCT2 MISSION® esiRNA $(3 \mu \mathrm{g} /$ mouse in $100 \mu \mathrm{L}$ isotonic saline solution, $n=15$, Sigma-Aldrich) daily for 10 days. Mice injected with Ctrl esiRNA (the sequence of the Ctrl esiRNA has no significant homology with any sequence in the databases) were used as negative controls. Mice received in total two cycles of esiRNA treatment (Dong et al. 2016). The protocols involved in animal work, strictly conformed to the National Institutes of Health guide for the Care and Use of Laboratory Animals (NIH Publications No. 8023, revised 1978), were approved by Institutional Animal Care and Use Committee of Luoyang Central Hospital Affiliated to Zhengzhou University (Approval \#: LYCH2016-0354Y). 


\section{Assessment of male fertility and epididymal parameters}

Effects of SVCT2 ablation on male fertility and epididymal parameters were determined at 70 days after siRNA treatment, according to a previous report (Zhang et al. 2018). One male mouse was mated with two naïve females. Once vaginal plugs were identified on the morning check, the female mouse with vaginal plugs was immediately replaced with another new one. A total of seven males in each experimental group were subjected to mating test within 21 days. Females with copulation plugs were finally checked for pregnancy and litter size. Characterization of the density and motility of caudal epididymal sperms was performed as described in detail in a previous report (Ma et al. 2010).

\section{Measurement of serum testosterone and testicular apoptosis}

Upon sodium pentobarbital anesthesia $(0.05 \mathrm{mg} / \mathrm{g}$ body weight, i.p.), blood samples were collected from mouse orbital sinus, and serum testosterone levels were assessed using the Testosterone Parameter Assay Kit (R\&D Systems), as per the manufacturer's instructions. Testicular apoptosis was determined in testicular homogenates using an apoptosis ELISA kit (Roche Diagnostics), following the manufacturer's instructions. Final spectrophotometry was performed at $405 \mathrm{~nm}$ on a Bio-Rad microplate reader.

\section{Cell treatment}

Primary SCs were isolated and purified from adult mice (10-week-old), using collagenase and DNase digestion combined with hypotonic treatment, as described elsewhere (Dong et al. 2016). Briefly, testes were decapsulated and seminiferous tubules were incubated with $0.1 \%(\mathrm{w} / \mathrm{v})$, type IX collagenase (Sigma-Aldrich) at room temperature (RT) for $15 \mathrm{~min}$. The resultant mixture was digested in culture medium containing $0.04 \%$ DNase I (Sigma-Aldrich) at $34^{\circ} \mathrm{C}$ for $30 \mathrm{~min}$. The seminiferous tubules were subsequently incubated in $1 \times$ Hanks fluid (pH 7.4) containing $0.04 \%$ DNase I, $0.05 \%$ hyaluronidase, and $0.5 \%$ trypsin for at least $10 \mathrm{~min}$ at $34^{\circ} \mathrm{C}$ with agitation. After being centrifuged at $100 \boldsymbol{g}$ and at $60 \boldsymbol{g}$ for $3 \mathrm{~min}$, respectively, cells in the supernatant were harvested and cultured for another $48 \mathrm{~h}$. Cells were then hypotonically treated with $20 \mathrm{mM}$ Tris $(\mathrm{pH} 7.4)$ at $22^{\circ} \mathrm{C}$ for $2.5 \mathrm{~min}$ to lyse residual germ cells (Xiao et al. 2011). The purity of primary SCs was confirmed using a real-time PCR.
The murine Sertoli cell line TM4, obtained from American Type Culture Collection, was maintained in a 1:1 mixture of Ham'S F12 medium and DMEM with $1.2 \mathrm{~g} / \mathrm{L}$ sodium bicarbonate and $15 \mathrm{mM}$ HEPES, 92.5\% horse serum and $5 \%$ fetal bovine serum. On day 3 of cell culture, cells were incubated for $48 \mathrm{~h}$ with FSH $(100 \mathrm{ng} / \mathrm{mL})$ or bFGF (30 ng/mL) to stimulate lactate production. Both FSH and bFGF were purchased from Sigma-Aldrich. Primary Leydig cells (LCs) and germ cells (GCs) were prepared based on the methods described in previous reports (Zhao et al. 2008, Li et al. 2011). To stably knockdown the SVCT2 expression, TM4 cells were transfected with SVCT2 pCMV-Neo-shRNA or with Ctrl shRNA (SigmaAldrich) using Lipofectamine ${ }^{\mathrm{TM}} 3000$ (Thermo Fisher Scientific), followed by selection with $0.5 \mu \mathrm{g} / \mathrm{mL}$ G418 (Thermo Fisher Scientific), following the manufacturer's instructions. TM4 $4^{\text {SVCT2-I- } / H A-H I F 1 ~} \alpha^{\text {P402A/P564A }}$ cells were generated by transfection of HA-HIF1 $\alpha^{\mathrm{P} 402 \mathrm{~A} / \mathrm{P} 564 \mathrm{~A}}-\mathrm{pBabe-}$ puro followed by selection with $50 \mathrm{ng} / \mathrm{mL}$ puromycin (Sigma-Aldrich). HA-HIF1 $\alpha^{\text {P402A/P564A-pBabe-puro was }}$ a gift from William Kaelin (Addgene plasmid \# 19005; http://n2t.net/addgene:19005; RRID:Addgene_19005). TM4 cells, which are established cell line cultures derived from immature not adult mice, possess major properties of normal SCs (Luo et al. 2018).

\section{Determination of lactate and ammonium levels}

In this study, $10 \%(\mathrm{w} / \mathrm{v})$ testicular homogenates were prepared in pre-cold $0.5 \mathrm{M}$ monophosphoric acid, followed by incubation at $4^{\circ} \mathrm{C}$ for $20 \mathrm{~min}$ with $5 \mathrm{M}$ potassium carbonate solution to eliminate the acid. After being centrifuged at $1.0 \times 10^{4} \boldsymbol{g}$ for $15 \mathrm{~min}$, the supernatants were collected and subjected to measurement of intratesticular lactate levels using a Lactate Colorimetric/Fluorometric Assay Kit (BioVision, Milpitas, CA, USA).

In another experimental setting, following the stimulation with FSH (100 ng/mL) or bFGF (30 ng/mL) for $48 \mathrm{~h}$, the conditioned cell culture media were harvested and subjected to measurement of lactate and ammonium levels using the BioVision Lactate Colorimetric/ Fluorometric Assay Kit and an Ammonia Assay Kit (Abcam), respectively.

\section{Real-time PCR}

Total RNA was isolated with the aid of E.Z.N.A.® HP Total RNA Kit (Omega Bio-tek, Norcross, GA, USA). After a DNase Digestion for RNA purification using RNeasy Kit (Qiagen), RNA samples were subjected to 
RT using QuantiTect RT Kit (Qiagen). Subsequent realtime PCR was performed on a Step-One Real-Time PCR System (Applied Biosystems). Amplification of $18 S$ was used as an internal control. Primer used were Svct2 (NM_018824.2), 5'-GTGCGATCGGCGGGAC-3' and 5'-GTTGGCCTGGAGTGGTTACA-3'; $18 \mathrm{~S}$ (M10098.1), 5'-CTCGCCGCGCTCTACCTACCTA-3' and 5'-ATGAGCCATTCGCAGTTTCACTGTA-3'. Primers for other target genes have been reported elsewhere (Zhang et al. 2018). The relative expression levels of target genes were determined using the comparative $\Delta \Delta \mathrm{Ct}$ method ( $\mathrm{Li}$ et al. 2011).

\section{Immunoblotting}

Protein samples were prepared from cultured cells and testicular tissues using Minute ${ }^{\mathrm{TM}}$ Protein Extraction Kit (Invent Biotechnologies, Plymouth, MN, USA). After protein identification on a NanoDrop ${ }^{\mathrm{TM}}$ spectrophotometer (Thermo Fisher Scientific), $30 \mu$ g of protein samples were subjected to SDS-PAGE, and were then transferred onto a PVDF membrane (Thermo Fisher Scientific). Membranes were incubated at $4^{\circ} \mathrm{C}$ overnight with different primary antibodies (Supplementary Table 1, see section on supplementary materials given at the end of this article). Subsequent chemiluminescent detection of the target proteins was performed on a Freedom Rocker ${ }^{\mathrm{TM}}$ BlotBot ${ }^{\circledR}$ automated blot processor, following the manufacturer's instructions, with $\beta$-actin serving as the loading control.

\section{Morphological examination}

Bouin's fluid-fixed paraffin-embedded testicular tissues were subjected to a $5-\mu$ m-sectioning, followed by staining with a Hematoxylin and Eosin Staining Kit (Beyotime, Shanghai, China).

To reveal the localization of SVCT2 protein in situ, $4 \%$ paraformaldehyde-fixed paraffin-embedded testicular sections were routinely deparaffinized and rehydrated, and were subjected to citrate buffer antigen retrieval at $95^{\circ} \mathrm{C}$ for $20 \mathrm{~min}$. After blocking of endogenous peroxidase by incubating slides in $0.3 \% \mathrm{H}_{2} \mathrm{O}_{2}$ for $20 \mathrm{~min}$ at room temperature (RT), sections were incubated at $4^{\circ} \mathrm{C}$ overnight with an SVCT2 antibody (Supplementary Table 1), followed by sequential incubation at RT with biotinylated second antibodies and streptavidin-peroxidase complex (Vector Lab, Burlingame, CA, USA) for 1 h, respectively. Final immunoreaction was developed at RT for 10 min using

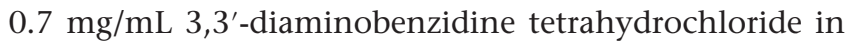
$1.6 \mathrm{mg} / \mathrm{mL}$ urea hydrogen peroxide (Sigma-Aldrich).
To visualize the subcellular localization of SVCT2 protein, TM4 cells were treated for $48 \mathrm{~h}$ with $100 \mathrm{ng} / \mathrm{mL}$ $\mathrm{FSH}$, and were then fixed in 4\% paraformaldehyde at RT for $20 \mathrm{~min}$. Upon completion of incubation with blocking solution (10\% donkey serum, $0.5 \%$ BSA plus $0.3 \%$ triton $\mathrm{X}-100$ in PBS) for $30 \mathrm{~min}$, cells were incubated with the antiHIF- $1 \alpha$ antibody at $4^{\circ} \mathrm{C}$ overnight. Final immunoreactions were developed by incubation with FITC 488-conjugated second antibody at RT for $1 \mathrm{~h}$, followed by observation under a Zeiss 510 confocal microscope.

\section{Luciferase reporter assay}

pLightSwitch-Luc-Ldha and the corresponding blank vector were obtained from SwitchGear Genomics (Shanghai, China). For reporter assay, TM44vCT2-/-, TM4 or TM4 ${ }^{\text {SVCT2-/- } / H A-H I F 1 ~} \alpha^{\text {P402A/P564A }}$ cells were transfected with 100 ng reporter plasmids using Lipofectamine ${ }^{\mathrm{TM}}$ 3000. 48 $\mathrm{h}$ after transfection, cells were stimulated with $100 \mathrm{ng} / \mathrm{mL}$ FSH for another $12 \mathrm{~h}$, followed by measurement of the relative luciferase activities using the LightSwitch reporter assay system, as instructed by the manufacturer.

\section{Co-immunoprecipitation (Co-IP)}

TM4svCT2-/- or TM4 cells were transfected with pCMV6Myc-Hif1a using Lipofectamine ${ }^{\mathrm{TM}}$ 3000. 48 h later, cells were stimulated with $100 \mathrm{ng} / \mathrm{mL}$ FSH for another $48 \mathrm{~h}$, followed by Co-IP assay as described in detail in a previous report (Zhang et al. 2012).

\section{Data presentation and statistical analysis}

Representative results are presented from at least three independent experiments. All outlier data points have been included in the main statistical analysis. Quantitative data were expressed as the mean \pm s.e.m. Results were analyzed for statistically significant differences using Student's $t$-test or ANOVA plus Tukey's test. $P<0.05$ was considered statistically significant.

\section{Results}

\section{SVCT2 is specifically expressed in SCs in murine testis}

As a first step to explore the testicular action of SVCT2, we examined its expression pattern in 10-week-old mouse testis. Immunoblotting with the anti-SVCT2 antibody revealed a single band of the target protein in the whole blot. By contrast, immunoblotting with the preabsorbed 
primary antibody failed to detect any positive signal, verifying the antibody specificity (Fig. 1A). Subsequent PCR and immunoblotting analyses in different testicular cells demonstrated that SVCT2 was exclusively expressed in SCs (Fig. 1B). In line with these results, our immunostaining showed that SVCT2 protein was enriched in the cytoplasm of SCs (arrows in Fig. 1C). Moreover, evaluation of SVCT2 expression by immunoblotting and real-time PCR analyses showed that SVCT2 expression began to emerge from postnatal day 14 (corresponding to the appearance of pachytene spermatocytes), and increased thereafter, with the highest levels being observed in adulthood (Fig. $1 \mathrm{D}$ and E). These findings suggest that SVCT2 expression is developmentally regulated in mouse testis.

\section{In vivo knockdown of SVCT2 expression significantly impairs male infertility by inducing oligozoospermia and asthenospermia}

To understand the biological effects of testicular SVCT2 expression, we knocked down the in vivo SVCT2 expression by employing a previously validated protocol (Fig. 2A) (Gonzalez-Herrera et al. 2006, Dong et al. 2016). Mice received i.p. injections with SVCT2 MISSION® esiRNA on daily basis for consecutive 10 days, followed by a 25-day break. At the end of 79 days after first injection, mice were sacrificed and testes were harvested. Real-time PCR revealed that esiRNA decreased the Svct2 mRNA content in testes by $\sim 57.3 \%$ within two cycles of siRNA treatment (Fig. $2 \mathrm{~B}$ ). The effectiveness of esiRNA on the inhibition of SVCT2 expression was further confirmed at the protein level by immunoblotting (Fig. 2C) and immunohistochemistry (Fig. 2D). Consistently, immunoblotting with the protein samples prepared from the primary SCs from esiRNAtreated testes also showed a significant reduction in the SVCT2 protein levels, compared to those from Ctrl siRNA-treated or naïve testes (Fig. 2E). Consequently, knockdown of SVCT2 expression had no effects on serum testosterone levels (Fig. 2F), but resulted in a noticeable change in testicular morphology, including desquamation of GCs, loss of lumen inside seminiferous tubules and decrease of testis weight/body weight ratio (Fig. 2G and

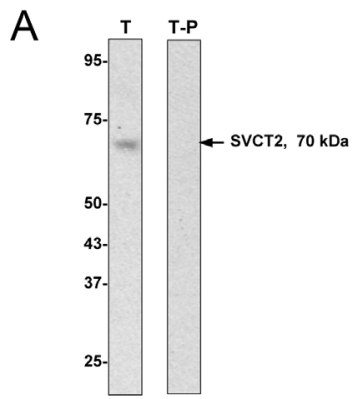

B

C
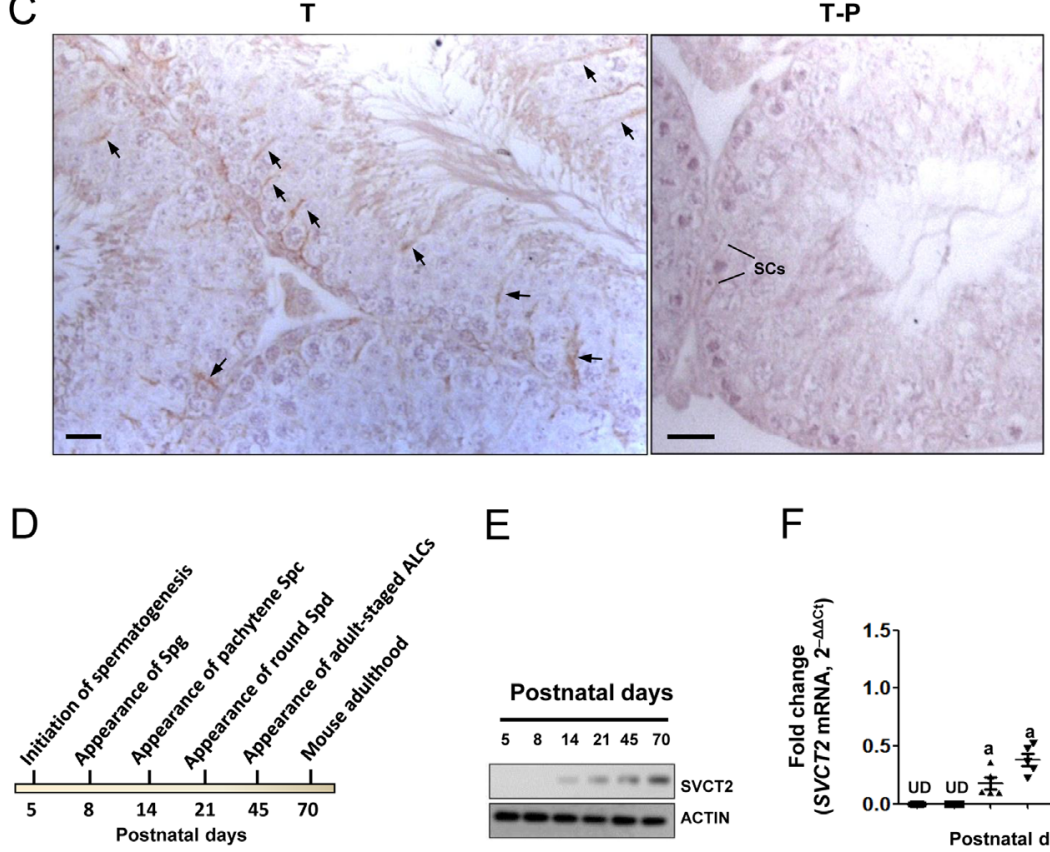

$E$

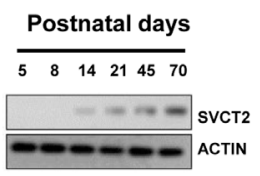

$\mathrm{F}$
(C) 2021 Society for Endocrinology Published by Bioscientifica Ltd. Printed in Great Britain

\section{Figure 1}

Expression pattern of SVCT2 in mouse testis. (A) Immunoblot stained with an anti-SVCT2 antibody or a preabsorbed serum demonstrated the specificity of this antibody. The protein samples were harvested from testes of 10-week-old mice. (B) Expression profile of SVCT2 was evaluated in different testicular cells and in adult mouse testis using PCR and immunoblotting assays, respectively. 185 and $\beta$-actin served as internal controls. (C) Immunohistochemical analysis in mouse testis (T) revealed a distinct cytoplasmic localization of SVCT2 in SCs (arrows). Replacement of the primary antibody with preabsorbed primary antibody $(\mathrm{P})$ abolished the positive immunostaining, confirming the specificity of the assay. Bar, $25 \mu \mathrm{m}$. (D) Diagram of the stages of murine spermatogenesis during postnatal development. (E) Immunoblotting analysis of testicular SVCT2 protein levels throughout postnatal development. (F) Real-time PCR analysis of testicular Svct2 mRNA levels throughout postnatal development. Different superscript letters denote groups that are statistically different $(P<0.05)$. UD, undetectable. 
A

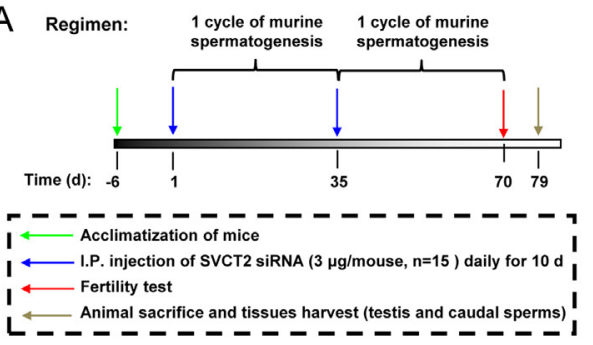

D

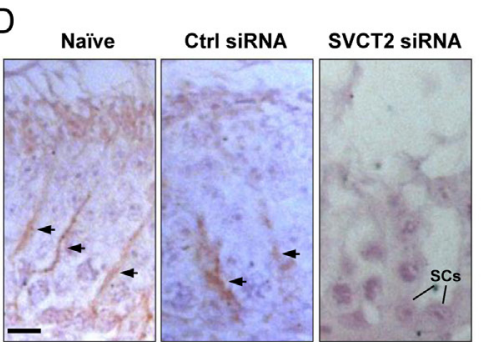

E

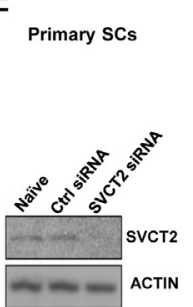

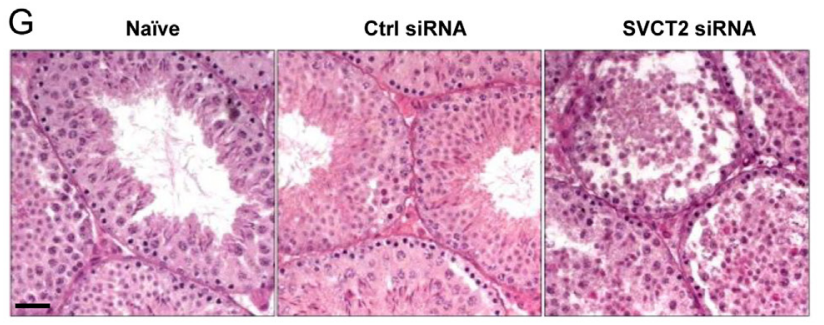

I

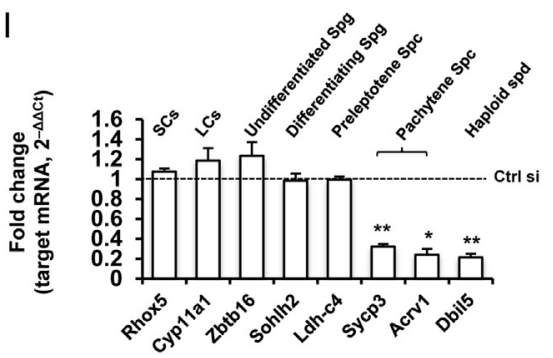

$\mathrm{F}$

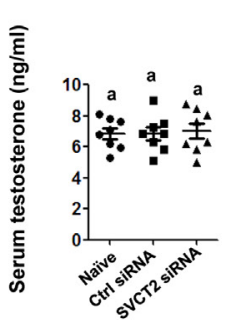

B

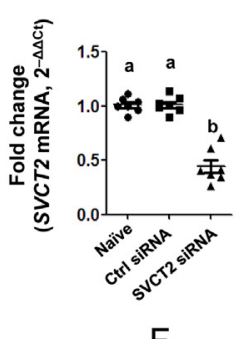
Testis

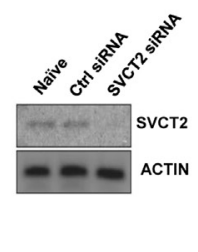

$\mathrm{H}$

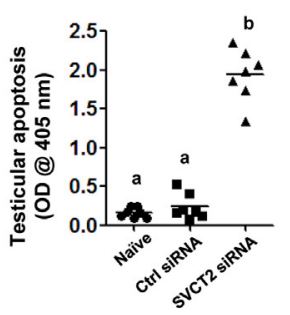

Figure 2

In vivo knockdown of SVCT2 expression causes defective spermatogenesis in mouse testis. (A) Schematic representation of the experimental procedure used in the in vivo SVCT2 SiRNA treatment. (B) At the end of 79 days following the first injection with SVCT2 SiRNA, the efficiency of SVCT2 knockdown was verified at the mRNA level using real-time PCR analysis in mouse testis $(n=7)$. Different superscript letters denote groups that are statistically different $(P<0.05)$. (C) At the end of 79 days following the first injection with SVCT2 siRNA, efficiency of SVCT2 knockdown was verified at the protein level using immunoblotting assay in mouse testis $(n=7)$. (D)

Immunohistochemical analysis of testicular SVCT2 expression 79 days after the in vivo siRNA treatment. (E) Primary SCs were isolated from mouse testis at the end of 79 days following the first injection with SVCT2 siRNA, followed by immunoblotting assay. (F) ELISA analysis of serum testosterone levels 79 days after the in vivo siRNA treatment $(n=7)$. Different superscript letters denote groups that are statistically different $(P<0.05)$. (G) Effects of in vivo SVCT2 knockdown on testicular morphology were determined using H\&E staining 79 days after the in vivo siRNA treatment. Bar, $25 \mu \mathrm{m}$. (H) ELISA analysis of testicular apoptosis after the in vivo SVCT2 siRNA treatment. Different superscript letters denote groups that are statistically different $(n=7$, $P<0.05)$. (I) The deleterious effects of in vivo SVCT2 knockdown on the spermatogenic differentiation was evaluated by real-time PCR analyses using specific primers for Rhox 5 (SCs), Cyp11a1 (Leydig cells), Zbtb16 (undifferentiated spermatogonia), Sohlh2 (differentiating spermatogonia), $L d h$ - $c 4$ (preleptotene spermatocytes), Syсp3 (pachytene spermatocytes) and for Acrv1 and Dbil5 (haploid spermatids), respectively. Results presented as mean \pm S.E.M. of three independent experiments. ${ }^{*} P<0.05$ and $* * P<0.01$ when compared to the values in naïve testis. () After two cycles of SVCT2 siRNA injection as described in 'Materials and methods' section, mice were sacrificed and intratesticular levels of $g$ lactate were determined using biochemical assays. Different superscript letters denote groups that are statistically different $(P<0.05)$.
Supplementary Fig. 1) and increase in germ cell apoptosis ( 5.4-fold, Fig. 2H). In keeping with the histological changes, SVCT2 deficiency significantly impaired male fertility by causing oligozoospermia and asthenospermia (Table 1). Of note, SVCT2 was not expressed in mouse epididymis (Supplementary Fig. 2). To clarify at which stage the spermatogenesis was blocked by SVCT2 knockdown, we performed qPCR analyses on testis RNA from Ctrl siRNA or esiRNA-treated testes using specific primers for various testicular cell types (Zhang et al. 2018). SVCT2 deficiency caused more than $\sim 62.8 \%$ reduction in the expression levels of $S y c p 3, A c r v 1$ and Dbil5 transcripts
(Fig. 2I), indicating that the absolute numbers of haploid cells (round and elongated spermatids) and tetraploid cells (mainly pachytene spermatocytes) were significantly decreased in esiRNA-treated testes. Given that the differentiation of tetraploid spermatocytes and haploid spermatids is solely fueled by Sertoli cell-produced lactate, we tended to believe that the germ cell loss by SVCT2 deficiency might be ascribed to a disturbance in lactate metabolism. In favor of our hypothesis, biochemical analysis using the testicular homogenates uncovered a $\sim 57.4 \%$ reduction in the intratesticular lactate levels in esiRNA-treated testes, compared to those from Ctrl 
Table 1 Assessment of male fertility and epididymal parameters after in vivo transfection.

\begin{tabular}{|c|c|c|c|c|c|}
\hline \multirow[b]{2}{*}{ Experimental groups } & \multicolumn{3}{|c|}{ Reproductive capacity } & \multicolumn{2}{|c|}{ Characteristics of epididymal sperms } \\
\hline & $\begin{array}{c}\text { Pregnancies/females } \\
\text { mated }\end{array}$ & Litter size & $\begin{array}{c}\text { Number of } \\
\text { males mated }\end{array}$ & $\begin{array}{c}\text { Number of sperm } \\
\text { (10\%/epididymis) }\end{array}$ & $\begin{array}{l}\text { Progressive } \\
\text { motility (\%) }\end{array}$ \\
\hline Naïve & $22 / 27(81.5 \%)^{a}$ & $8.2 \pm 2.4^{a}$ & 7 & $32.6 \pm 2.3^{a}$ & $41.5 \pm 1.9 a$ \\
\hline Ctrl siRNA & $20 / 24(83.3 \%)^{a}$ & $7.9 \pm 1.3^{a}$ & 7 & $30.9 \pm 1.1^{a}$ & $40.2 \pm 2.2^{a}$ \\
\hline SVCT2 SiRNA & $4 / 26(15.4 \%)^{b}$ & $2.7 \pm 0.8^{b}$ & 7 & $17.4 \pm 0.7^{b}$ & $10.6 \pm 3.2^{b}$ \\
\hline
\end{tabular}

Different superscript letters denote groups that are statistically different in the same category $(P<0.05)$.

siRNA-treated or naïve testes (Fig. 2J). Together, SVCT2 deficiency caused qualitative and quantitative defects during spermatogenesis.

\section{Supplement with the exogenous lactate ameliorates SVCT2 deficiency- impaired spermatogenesis}

To validate the biological effects of testicular SVCT2 on lactate production, we provided the mice with sodium L-lactate by i.p. injection at the same time of siRNA treatment (Fig. 3A). Apparently, supplement with the exogenous lactate had no effects on the expression levels of SVCT2 in mouse testis (Fig. 3B and C). However, replenishment of exogenous lactate successfully rescued the loss of testis weight (Supplementary Fig. 1), and improved SVCT2 deficiency-induced GCs desquamation and restored the lumen structure in the majority of seminiferous tubules (Fig. 3D). In line with these histological changes, replenishment of exogenous lactate prevented the SVCT2 deficiency-induced GCs apoptosis by $\sim 56.4 \%$ (Fig. 3E), and significantly ameliorated the male fertility and epididymal parameters in esiRNAtreated testis (Table 2). The latter was likely due to a partial restorement of the absolute numbers of tetraploid spermatocytes and haploid spermatids, as revealed by qPCR analyses (Fig. 3E).

\section{Ablation of the endogenous SVCT2 expression attenuates FSH/bFGF-stimulated lactate synthesis in TM4 cells}

To further explore the functional details of SVCT2 in lactate metabolism, we generated the TM445CT2-/- cells using shRNA transfection. The successful establishment

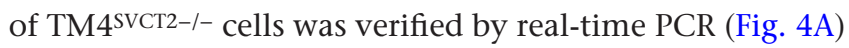
and immunoblotting assays (Fig. 4B). As a result, the FSH/ bFGF-stimulated lactate production and the metabolic waste product ammonium during lactate synthesis were both was significantly decreased in conditioned media from TM4 $4^{\text {SVCT2-l- }}$ cells, as compared to naïve or Ctrl
shRNA-treated TM4 cells. Of note, SVCT2 depletion had no effects on the basal levels of lactate synthesis in TM4 cells (Fig. 4C and D). Spurred by the metabolic phenotype, we sought to determine the expression levels of several core genes known to be essential for lactate synthesis in SCs (Fig. 4E) (Zhang et al. 2018). Upon stimulation with FSH or bFGF, expression levels of all the target transcripts studied were significantly induced in naïve or Ctrl shRNA-treated TM4 cells. By contrast, FSH/bFGF failed to stimulate the expression of Ldha mRNA in the TM4 $4^{\text {SVCT2-I- }}$ cells (Fig. 4F). Thus, SVCT2 depletion may cause defects at the last step of lactate synthesis in SCs.

\section{SVCT2 deficiency attenuates the HIF-1 $\alpha$-elicited transactivation of Ldha gene by inducing ubiquitination and instability of HIF-1 $\alpha$ during lactate synthesis}

During the complicated lactate synthesis in SCs, expression of Ldha gene is subjected to a delicate control at the transcriptional level (Jungmann et al. 1998). Indeed in our study, treatment with $100 \mathrm{ng} / \mathrm{mL} \mathrm{FSH}$ for $12 \mathrm{~h}$ significantly stimulated the promoter activity of Ldha gene in TM4 cells, while this stimulatory effect was totally abolished in the TM4Svct2-l- cells (Fig. 5A). As further exploration of the molecular basis underlying the aforementioned phenotype, we unexpectedly observed that FSH-induced HIF-1 $\alpha$ expression (Fig. 5B) and nuclear translocation (Fig. 5C) were totally lost in the TM4 $4^{\text {svCT2-I- }}$ cells. Moreover, SVCT2 depletion had no effects on the expression levels of Hif1a mRNA (Fig. 5D), but resulted in a dramatic increase in the ubiquitination of HIF- $1 \alpha$ protein in FSH-challenged TM4 cells (Fig. 5E). To further establish whether HIF1- $\alpha$ contributes to SVCT2's function in lactate production, we performed rescue experiments using a HA-tagged constitutively activated HIF-1 $\alpha$ mutant construct (HA-HIF1 $\alpha^{\mathrm{P} 402 \mathrm{~A} / \mathrm{P} 564 \mathrm{~A}}$ ) (Yan et al. 2007). As expected, enforced overexpression of HA-HIF1 $\alpha^{\mathrm{P} 402 \mathrm{~A} / \mathrm{P} 564 \mathrm{~A}}$ restored the nuclear expression of HIF1- $\alpha$, even in the absence of FSH stimulation, in TM4SVCT2-/- cells (Fig. $5 \mathrm{~F}$ and $\mathrm{G})$. Consequently, constitutive activation of 


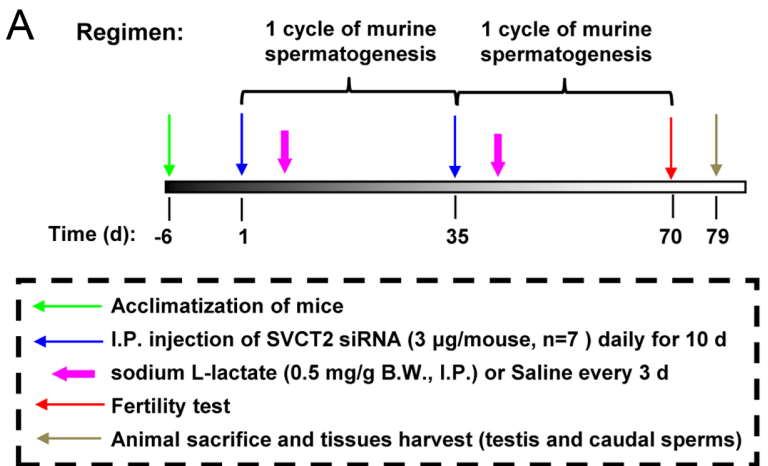

B

Testis

C

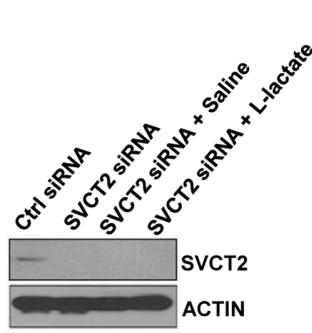

Testis

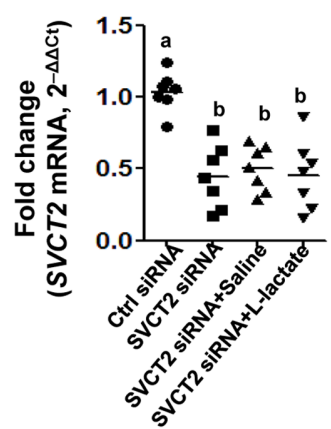

E

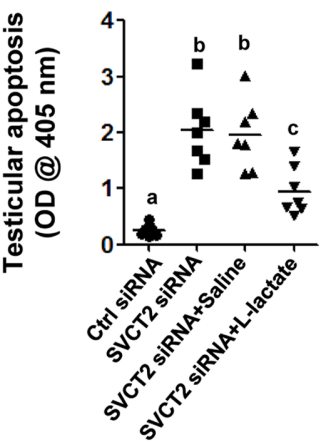

Testis

$\mathrm{F}$
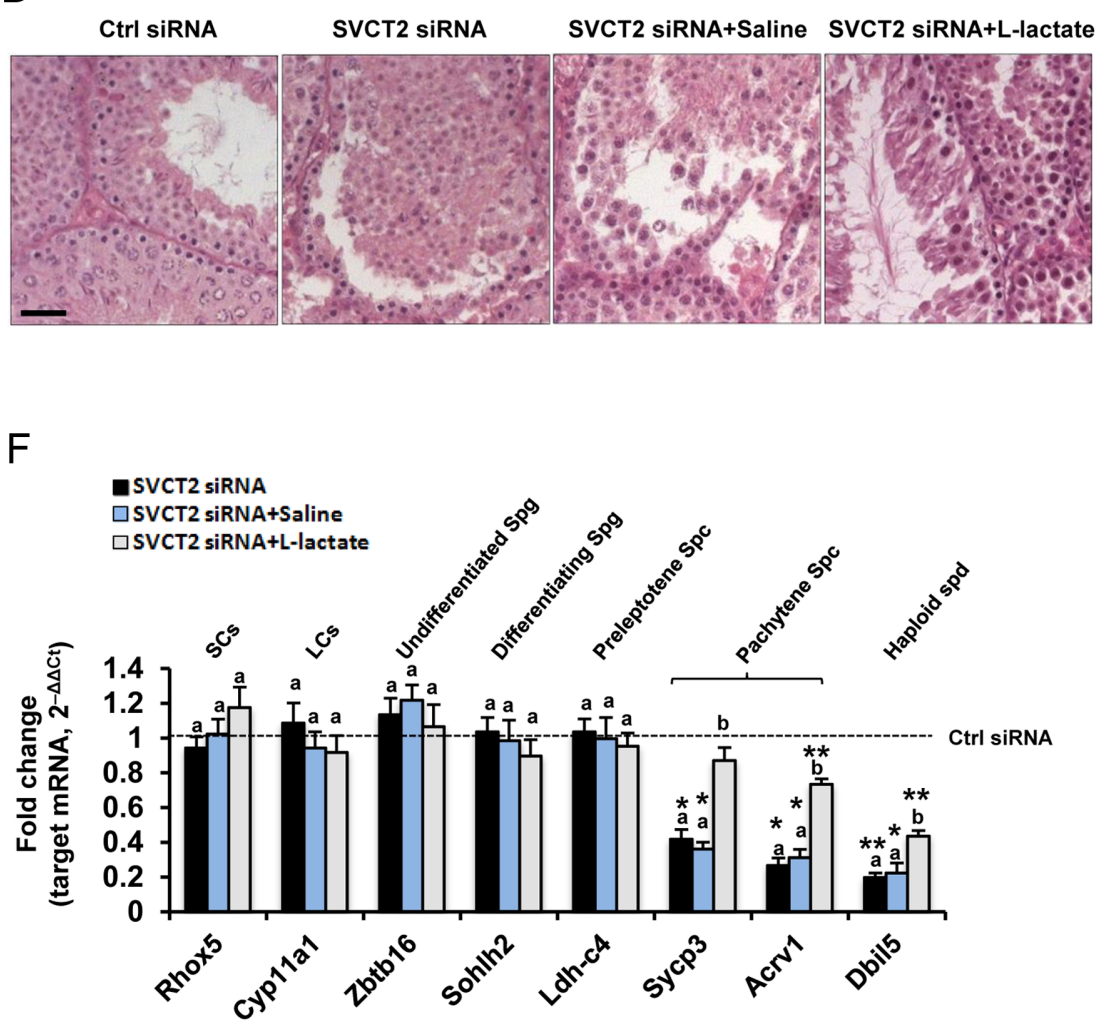

Figure 3

Supplement with exogenous lactate ameliorates spermatogenic defects in SVCT2 siRNA-treated testis. (A) Schematic representation of the experimental procedure for in vivo supplement with sodium L-lactate in our mouse model. (B) At the end of 79 days following the first injection with SVCT2 siRNA, efficiency of SVCT2 knockdown was verified at the protein level using immunoblotting assay in mouse testis $(n=7)$. (C) At the end of 79 days following the first injection with SVCT2 siRNA, efficiency of SVCT2 knockdown was verified at the mRNA level using real-time PCR analysis in mouse testis $(n=7)$. Different superscript letters denote groups that are statistically different $(P<0.05)$. (D) Effects of in vivo SVCT2 knockdown plus lactate supplementation on testicular morphology were determined using H\&E staining 79 days after the in vivo siRNA treatment. Bar, $25 \mu \mathrm{m}$. (E) ELISA analysis of testicular apoptosis after combined SVCT2 siRNA and lactate treatment. Different superscript letters denote groups that are statistically different $(n=7, P<0.05)$. (F) Effects of in vivo SVCT2 knockdown plus lactate supplementation on the spermatogenic differentiation was evaluated by real-time PCR analyses, as described previously. Results presented as mean \pm S.E.M. of three independent experiments. $* P<0.05$ and $* * P<0.01$ when compared to the values in naïve testis. Different superscript letters denote groups that are statistically different $(P<0.05)$.

HIF-1 $\alpha$ successfully restored the FSH-stimulated Ldha transactivation (Fig. 5H) and lactate production (Fig. 5I) in TM4 $4^{\text {SVCT2-I- }}$ cells. Considering that HIF- $1 \alpha$ pathway activation regulates fundamentally the lactate production in SCs (Galardo et al. 2017), and mouse Ldha promoter contained two putative binding sites of HIF1- $\alpha$ and HIF1- $\alpha$ positively regulated the transactivation of the Ldha gene (Supplementary Fig. 3), we have identified SVCT2's 
Table 2 Effects of in vivo SVCT2 knockdown, along with the supplementation with L-lactate, on male fertility and epididymal parameters.

\begin{tabular}{|c|c|c|c|c|c|}
\hline \multirow[b]{2}{*}{ Experimental groups } & \multicolumn{3}{|c|}{ Reproductive capacity } & \multicolumn{2}{|c|}{ Characteristics of epididymal sperms } \\
\hline & $\begin{array}{c}\text { Pregnancies/females } \\
\text { mated }\end{array}$ & Litter size & $\begin{array}{c}\text { Number of } \\
\text { males mated }\end{array}$ & $\begin{array}{l}\text { Number of sperm } \\
\text { (10\%/epididymis) }\end{array}$ & $\begin{array}{l}\text { Progressive } \\
\text { motility (\%) }\end{array}$ \\
\hline Ctrl siRNA & $20 / 25(80.0 \%)^{a}$ & $8.8 \pm 1.7 a$ & 7 & $34.9 \pm 4.8^{a}$ & $46.3 \pm 4.8^{a}$ \\
\hline SVCT2 SiRNA & $5 / 27(18.5 \%)^{b}$ & $3.1 \pm 0.8^{b}$ & 7 & $15.6 \pm 1.2^{b}$ & $12.4 \pm 3.5^{b}$ \\
\hline \multicolumn{6}{|l|}{ SVCT2 SIRNA } \\
\hline Saline & $7 / 32(21.8 \%)^{b}$ & $3.6 \pm 0.4^{b}$ & 7 & $14.8 \pm 1.7^{b}$ & $16.4 \pm 2.2^{b}$ \\
\hline Sodium L-lactate & $16 / 28(57.1 \%)^{c}$ & $7.2 \pm 0.6 c$ & 7 & $24.3 \pm 2.4^{c}$ & $39.8 \pm 5.6^{a}$ \\
\hline
\end{tabular}

Different superscript letters denote groups that are statistically different in the same category $(P<0.05)$.

control of the HIF- $1 \alpha$ stability program in SCs as a major mechanism during lactate synthesis.

\section{Discussion}

To our knowledge, this is the first study to provide a comprehensive evaluation of the pattern of expression and functional implication of SVCT2 in mouse testis. Three main observations were obtained so far. First, testicular SVCT2 expression was exclusively enriched in SCs, and its expression was indispensible for normal spermatogenesis. Second, ablation of endogenous SVCT2 expression significantly impaired male fertility by disrupting the lactate production. Last, SVCT2 deficiency attenuated lactate synthesis by inducing the ubiquitination and degradation of HIF- $1 \alpha$ protein in FSHchallenged TM4 cells. Overall, it is tempting to consider SVCT2 as a novel modulator of the energy metabolism through posttranslational regulation of HIF1- $\alpha$ singling pathway in mouse testis.

When meiosis begins from puberty, the differentiation of tetraploid spermatocytes and haploid spermatids becomes more specialized and their biochemical machinery is insufficient to fulfill their metabolic demands. To this end, lactate produced by the adjacent SCs remains the sole energy source fueling the continuous dividing of these unique germ cells (Crisostomo et al. 2018). Intriguingly, SVCT2 expression began to emerge right after the appearance of tetraploid pachytene spermatocytes, as revealed by our profiling analysis using testicular samples from different postnatal ages (Fig. $1 \mathrm{D}, \mathrm{E}$ and F). These findings point to a close correlation between SVCT2 expression and energy requirement along postnatal testicular maturation.

Validation of the functional importance of SVCT2 expression in SCs was achieved using an in vivo siRNA

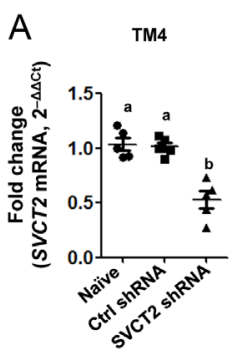

B TM4
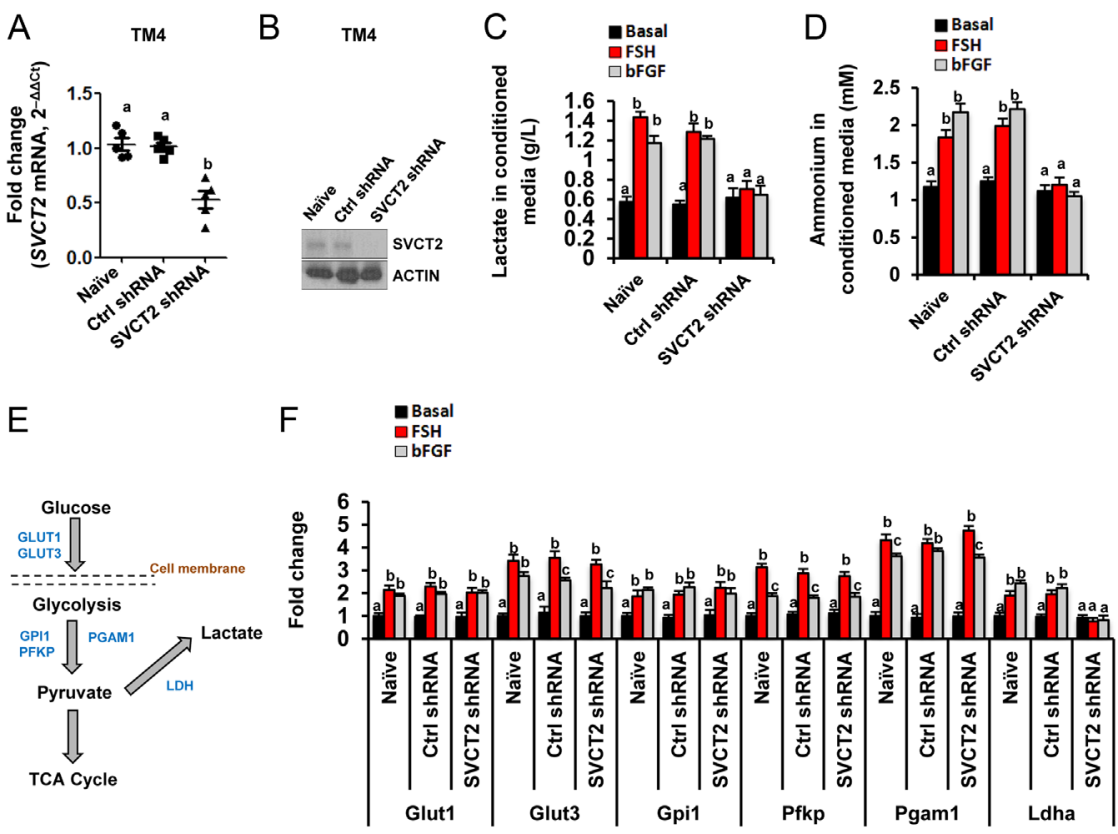

\section{Figure 4}

Identification of Ldha as the most affected target gene upon SVCT2 depletion in FSH/bFGFstimulated TM4 cells. (A) Generation of the TM4SVCT2-I- cells was validated at the mRNA level using real-time PCR analysis. Different superscript letters denote groups that are statistically different $(n=5, P<0.05)$. (B) Generation of the TM4SVCT2-I- cells was validated at the protein level using immunoblotting assay $(n=5)$. (C and D) Different TM4 cells were incubated for $48 \mathrm{~h}$ with FSH (100 ng/mL) or bFGF (30 ng/mL), followed by measurement of lactate and ammonium levels in culture media using a colorimetric assay kit. Different superscript letters denote groups that are statistically different $(n=5, P<0.05)$. (E) Schematic presentation depicting the main metabolic pathways responsible for lactate production in SCs. (F) Altered expression of genes impacting lactate metabolism in SCs transfected with SVCT2 shRNA or Ctrl shRNA were quantified by real-time PCR analysis. Different superscript letters denote groups that are statistically different $(n=4, P<0.05)$. 

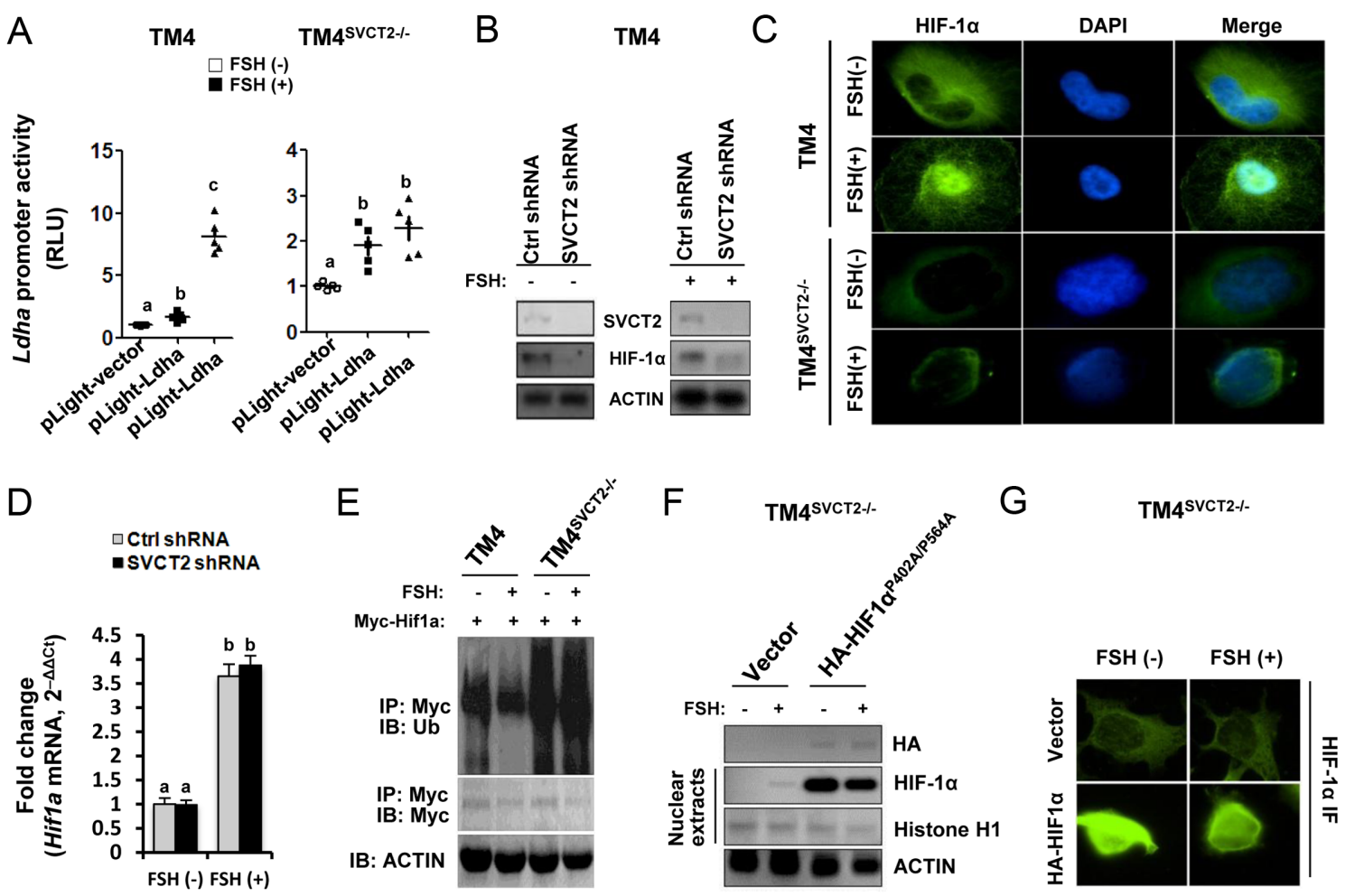

$\mathrm{H}$ TM4 ${ }^{\text {SVCT2-I }}$

I

TM4 ${ }^{\text {SVCT2-I- }}$
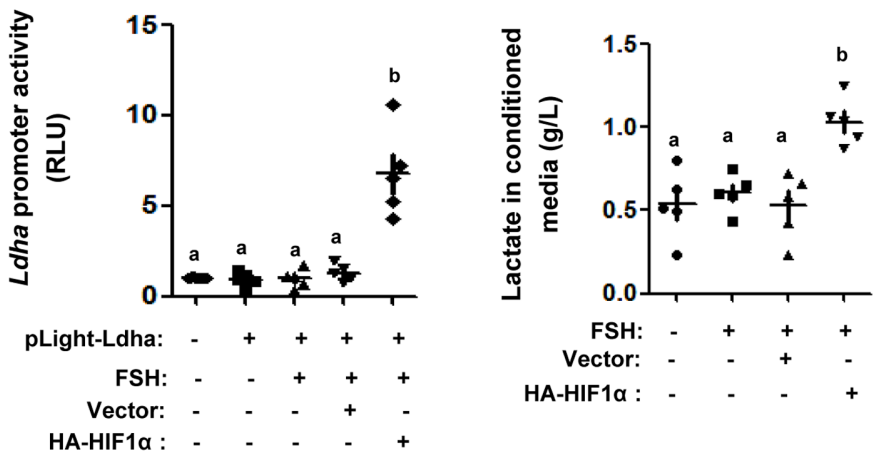

\section{Figure 5}

SVCT2 deficiency led to impaired lactate production and reduced Ldha mRNA expression, mainly through induction of the ubiquitination and subsequent degradation of HIF-1 $\alpha$ protein in stimulated SCS. (A) TM4SVCT2-I- or TM4 cells were transfected with 100 ng reporter plasmids using Lipofectamine 3000. Forty-eight hours after transfection, cells were stimulated with $100 \mathrm{ng} / \mathrm{mL} \mathrm{FSH}$ for another $12 \mathrm{~h}$, followed by measurement of the relative luciferase activities using the LightSwitch reporter assay system. Different superscript letters denote groups that are statistically different $(n=5, P<0.05)$. (B) TM4 or TM4SVCT2-I- cells were treated for $48 \mathrm{~h}$ with $100 \mathrm{ng} / \mathrm{mL}$ FSH, followed by immunoblotting assay $(n=4)$. (C) TM4 or TM45VCT2-I- cells were treated for $48 \mathrm{~h}$ with $100 \mathrm{ng} / \mathrm{mL} \mathrm{FSH}$, followed by evaluation of the subcellular localization of HIF-1 $\alpha$ using immunofluorescence plus observation under a confocal microscope. (D) TM4 or TM45VCT2-I- cells were treated for $48 \mathrm{~h}$ with $100 \mathrm{ng} / \mathrm{mL}$ FSH, followed by real-time PCR analysis. Different superscript letters denote groups that are statistically different $(n=4, P<0.05)$. (E) TM4SVCT2-I- or TM4 cells were transfected with pCMV6-Myc-Hif1a using Lipofectamine ${ }^{\mathrm{TM}}$ 3000. Forty-eight hours later, cells were stimulated with $100 \mathrm{ng} / \mathrm{mL}$ FSH for another $48 \mathrm{~h}$, followed by Co-IP assay using the antibody as indicated. (F)

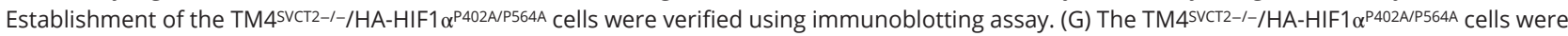
treated for $48 \mathrm{~h}$ with $100 \mathrm{ng} / \mathrm{mL} \mathrm{FSH}$, followed by evaluation of the subcellular localization of HIF-1 $\alpha$ using immunofluorescence plus observation under a

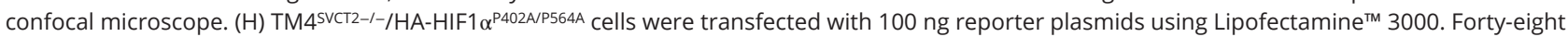
hours after transfection, cells were stimulated with $100 \mathrm{ng} / \mathrm{mL}$ FSH for another $12 \mathrm{~h}$, followed by measurement of the relative luciferase activities using the LightSwitch reporter assay system. Different superscript letters denote groups that are statistically different $(n=5, P<0.05)$. (I) TM45VCT2-I-I HA-HIF1 $\alpha^{P 402 A / P 564 A}$ cells were incubated for $48 \mathrm{~h}$ with FSH $(100 \mathrm{ng} / \mathrm{mL})$ followed by measurement of lactate levels in culture media using a colorimetric assay kit. Different superscript letters denote groups that are statistically different $(n=5, P<0.05)$. 
treatment. In this setting, inhibition of SVCT2 expression by $\sim 57.3 \%$ within two cycles of mouse spermatogenesis significantly impaired male fertility by causing oligozoospermia and asthenospermia (Table 1), and this phenotype was probably ascribed to the disrupted lactate synthesis. The latter hypothesis is supported by three lines of evidence: (1) The most affected GCs by SVCT2 deficiency are pachytene spermatocytes and haploid spermatids, as revealed by the qPCR analysis in siRNAtreated testis (Fig. 2I). (2 Intratesticular lactate content was noticeably reduced in siRNA-treated testis (Fig. 2J). (3) Most importantly, replenishment of sodium L-lactate by i.p. injection successfully ameliorated histological changes (Fig. 3D), restored germ cell composition (Fig. 3F) and improved male fertility in SVCT2-depleted mice (Table 2). Thus, the available data strongly suggest that normal occurrence of lactate synthesis in SCs requires proper levels of SVCT2 expression.

By generating the TM4 $4^{\mathrm{SVCT} 2-l-}$ cells, we further identified Ldha as the most affected gene in SVCT2depleted TM4 cells (Fig. 4F). The lactate dehydrogenase (LDH), mainly consisting of LDHA and/or LDHB subunits, catalyzes the final step of lactate synthesis, namely conversion of pyruvate to lactate (Huang et al. 2012). Concerning the testicular function of LDHA, two aspects should be emphasized. On one hand, despite the coexistence of LDHB subunit, LDHA is so far believed to be the most important LDH subunit in SCs (Rato et al. 2012, Schrade et al. 2016). Indeed in our study, repression of Ldha expression by SVCT2 depletion dramatically compromised FSH/bFGF-stimulated lactate production

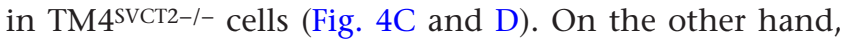
the expression of Ldha gene is tightly controlled at the transcriptional level. Previous studies have identified multiple cis-acting elements including functional sites for Sp1, c-Myc, CREB and AP1 located in the promoter region of Ldha gene. Likewise, a 8-bp cAMP-responsive element (CRE) has been found to be located at the -48/-41-bp upstream region of $L d h a$ promoter, and this site regulates fundamentally the Ldha transcription (Jungmann et al. 1998). Our results extend these understandings by identifying SVCT2 as an indispensible regulator of $L d h a$ mRNA expression during lactate synthesis in SCs. Because SVCT2 does not function as a transcription factor (Nualart et al. 2014), it is tempting to hypothesize that SVCT2 may regulate $L d h a$ mRNA expression in an indirect manner that requires cooperation of other key transcription factors.

It is well known that the transcriptional activity of the master transcription factor HIF- $1 \alpha$ is significantly increased under hypoxic conditions (Fanale et al.
2013). However, emerging data evidence that Hif1a transactivation can also be induced under certain normoxic conditions, including glucose metabolism, angiogenesis and maintenance of iron homeostasis (Haase 2006, Semenza 2010, Loboda et al. 2012). In this context, fragmentary information had previously pointed to a potent involvement of HIF- $1 \alpha$ signaling in the modulation of SCs lactate synthesis. FSH regulates Hif1a subunits expression and HIF- $1 \alpha$ transcriptional activity, at the same time of stimulating lactate production in SCs. Moreover, a higher HIF- $1 \alpha$ transcriptional activity is associated with an augmentation of Ldha mRNA levels in rat SCs (Galardo et al. 2017). In accordance with these pioneer findings, we have shown that mouse Ldha promoter contained two putative binding sites of HIF- $1 \alpha$, and HIF- $1 \alpha$ positively regulated the transactivation of the Ldha gene in FSH/bFGF-challenged SCs (Supplementary Fig. 3). Thus, it is very likely that the HIF- $1 \alpha$-mediated transcriptional regulatory program may represent a novel modulator of the function of lactate metabolism in SCs. By profiling TM4 $4^{\mathrm{SVCT} 2-/-}$ cells in the setting of ectopic Myc-Hif1a or HA-HIF1 $\alpha^{\mathrm{P} 402 \mathrm{~A} / \mathrm{P} 564 \mathrm{~A}}$ expression, we further demonstrated that SVCT2 deficiency caused impaired lactate production and reduced Ldha mRNA expression, mainly through induction of the ubiquitination and subsequent degradation of HIF- $1 \alpha$ protein in stimulated SCs (Fig. 5). In support of our observation, ascorbic acid has been shown to regulate osterix expression in osteoblasts by activation of prolyl hydroxylase and ubiquitinationmediated proteosomal degradation pathway (Xing et al. 2011). Therefore, regulation of the stability of the target protein via modulation of its ubiquitination status appears to be a general mechanism of ascorbic acid/SVCT2 system in energy metabolism. Furthermore, our findings support the idea that the lactate synthesis could utilize a mode of regulation that links the control of gene expression by key transcription factors and posttranslational modifications.

As the active component of vitamin C, AA serves as a vital protector of cells against oxidant stress. It regulates cell differentiation and is involved in signal transduction in many systems (Jurek et al. 2020). For example, AA treatment promotes osteogenic differentiation capability in periodontal ligament stem cells (PDLSCs) (Yang et al. 2020). Supplement with AA helps to maintain early NK cell differentiation by facilitating the demethylation of killer Ig-like receptors (KIR) (Wu et al. 2020). Likewise, vitamin $\mathrm{C} / \mathrm{AA}$ is involved in the differentiation of precursor cells throughout the whole brain (Salazar et al. 2016). From a mechanistic standpoint, the enhancement of intracellular concentrations of AA has been long 


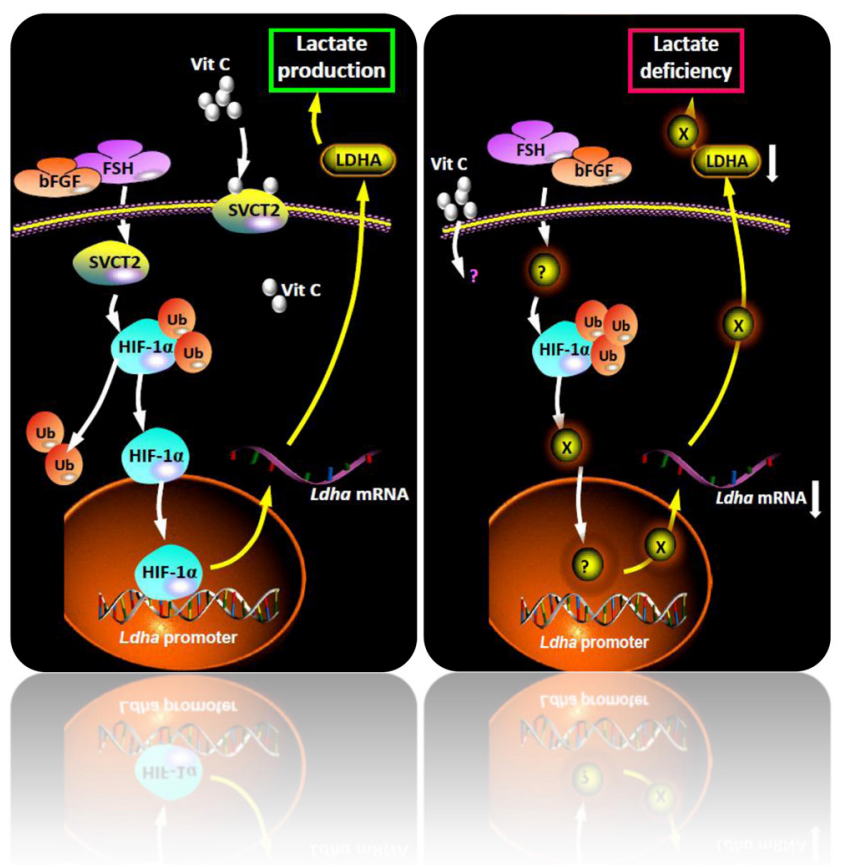

Figure 6

Model for involvement of the posttranslational modification of the HIF-1 $\alpha$ signaling pathway in SVCT2 deficiency-mediated lactate disruption.

considered to be the primary molecular mechanism underlying the physiological actions of SVCT2. In our study, however, SVCT2 is mainly considered as a signaling molecule, with no attempt to relate its expression to AA uptake and accumulation. In favor of our observation, Salazar et al. have reported that overexpression of SVCT2 induces neuronal branching and thereby activates the differentiation and maturation in neuroblastoma $\mathrm{N} 2 \mathrm{a}$ cells, whereas increasing intracellular vitamin $\mathrm{C}$ content via the overexpression of SVCT1 or AA supplementation does not completely reproduce the differentiating changes induced by SVCT2 overexpression (Salazar et al. 2016). Combined with our findings, the available data suggest that SVCT2 per se can function as a regulatory molecule in both differentiating (e.g. neuronal stem cells) and differentiated (e.g. SCs).

Based on the available data, we propose a novel role of SCs-expressing SVCT2. Upon energy requirement for the differentiation of meiotic and postmeiotic GCs, levels of lactate production-promoting hormones (e.g. FSH and bFGF) surge inside the testis. These hormones elicit a significant increase in SVCT2 expression, which inhibits ubiquitination and degradation of HIF- $1 \alpha$ via unidentified mechanism and then facilitates Ldha mRNA expression and subsequent lactate synthesis. Conversely, ablation of SVCT2 expression may result in the disruption of the ubiquitination of HIF- $1 \alpha$ protein and the inevitable HIF- $1 \alpha$ instability, followed by an unusual suppression of Ldha transcription and lactate production (Fig. 6). Limitations of the current study lie in two aspects: (1) We need to answer how SVCT2 regulates the ubiquitination of HIF- $1 \alpha$ protein in stimulated SCs. (2) A Sertoli cellspecific knockout of SVCT2 will be of great value to disclose the full involvement of SVCT2 in the control of lactate synthesis in vivo, and is currently under progress in our group.

\section{Supplementary materials}

This is linked to the online version of the paper at https://doi.org/10.1530/ JME-20-0101.

\section{Declaration of interest}

The authors declare that there is no conflict of interest that could be perceived as prejudicing the impartiality of the research reported.

\section{Funding}

This research did not receive any specific grant from funding agencies in the public, commercial, or not-for-profit sectors.

\section{Author contribution statement}

W F designed and supervised the experiments, contributed reagents and helped to analyzed the data and wrote the manuscript. G G, Z Y and W K performed the experiments and analyzed the data. $G \mathrm{G}$ helped to write the manuscript.

\section{Acknowledgement}

The authors are grateful for the research design and careful editing from Dr Wei Li (Department of Human Anatomy, Histology and Embryology, Fourth Military Medical University, Xi'an, China).

\section{References}

Aitken RJ \& Roman SD 2008 Antioxidant systems and oxidative stress in the testes. Advances in Experimental Medicine and Biology 636 154-171. (https://doi.org/10.1007/978-0-387-09597-4_9)

Angulo C, Castro MA, Rivas CI, Segretain D, Maldonado R, Yanez AJ, Slebe JC, Vera JC \& Concha II 2008 Molecular identification and functional characterization of the vitamin $\mathrm{C}$ transporters expressed by Sertoli cells. Journal of Cellular Physiology 217 708-716. (https:// doi.org/10.1002/jcp.21545)

Angulo C, Maldonado R, Pulgar E, Mancilla H, Cordova A, Villarroel F, Castro MA \& Concha II 2011 Vitamin C and oxidative stress in the seminiferous epithelium. Biological Research 44 169-180. (https://doi. org//S0716-97602011000200009)

Boussouar F \& Benahmed M 2004 Lactate and energy metabolism in male germ cells. Trends in Endocrinology and Metabolism 15 345-350. (https://doi.org/10.1016/j.tem.2004.07.003) 
Castro MA, Angulo C, Brauchi S, Nualart F \& Concha II 2008 Ascorbic acid participates in a general mechanism for concerted glucose transport inhibition and lactate transport stimulation. Pflugers Archiv 457 519-528. (https://doi.org/10.1007/s00424-008-0526-1)

Castro MA, Beltran FA, Brauchi S \& Concha II 2009 A metabolic switch in brain: glucose and lactate metabolism modulation by ascorbic acid. Journal of Neurochemistry 110 423-440. (https://doi.org/10.1111/ j.1471-4159.2009.06151.x)

Crisostomo L, Alves MG, Gorga A, Sousa M, Riera MF, Galardo MN, Meroni SB \& Oliveira PF 2018 Molecular mechanisms and signaling pathways involved in the nutritional support of spermatogenesis by Sertoli cells. Methods in Molecular Biology 1748 129-155. (https://doi org/10.1007/978-1-4939-7698-0_11)

Dawson EB, Harris WA, Teter MC \& Powell LC 1992 Effect of ascorbic acid supplementation on the sperm quality of smokers. Fertility and Sterility 58 1034-1039. (https://doi.org/10.1016/S0015-0282(16)55456-9)

Dong YS, Hou WG, Li Y, Liu DB, Hao GZ, Zhang HF, Li JC, Zhao J, Zhang S, Liang GB, et al. 2016 Unexpected requirement for a binding partner of the syntaxin family in phagocytosis by murine testicular Sertoli cells. Cell Death and Differentiation 23 787-800. (https://doi.org/10.1038/cdd.2015.139)

Dong BW, Jin XH, Yan CY, Yang T, Cai GQ \& Lu J 2017 Synergistic upregulation of NONO and PSPC1 regulates Sertoli cell response to MEHP via modulation of ALDH1A1 signaling. FEBS Letters 591 914-923. (https://doi.org/10.1002/1873-3468.12568)

Fanale D, Bazan V, Corsini LR, Caruso S, Insalaco L, Castiglia M, Cicero G, Bronte G \& Russo A 2013 HIF-1 is involved in the negative regulation of AURKA expression in breast cancer cell lines under hypoxic conditions. Breast Cancer Research and Treatment 140 505-517. (https://doi.org/10.1007/s10549-013-2649-0)

Galardo MN, Gorga A, Merlo JP, Regueira M, Pellizzari EH, Cigorraga SB, Riera MF \& Meroni SB 2017 Participation of HIFs in the regulation of Sertoli cell lactate production. Biochimie 132 9-18. (https://doi. org/10.1016/j.biochi.2016.10.006)

Gonzalez-Herrera IG, Prado-Lourenco L, Pileur F, Conte C, Morin A, Cabon F, Prats H, Vagner S, Bayard F, Audigier S, et al. 2006 Testosterone regulates FGF-2 expression during testis maturation by an IRES-dependent translational mechanism. FASEB Journal 20 476-478. (https://doi.org/10.1096/fj.04-3314fje)

Haase VH 2006 Hypoxia-inducible factors in the kidney. American Journal of Physiology: Renal Physiology 291 F271-F281. (https://doi. org/10.1152/ajprenal.00071.2006)

Huang L, Lin Y, Jin S, Liu W, Xu Y \& Zheng Y 2012 Alternative splicing of testis-specific lactate dehydrogenase $\mathrm{C}$ gene in mammals and pigeon. Animal Biotechnology 23 114-123. (https://doi.org/10.1080/10 495398.2011.652325)

Jain M \& Halder A 2012 Sertoli cell only syndrome: status of Sertoli cell maturation and function. Indian Journal of Endocrinology and Metabolism 16 S512-S513. (https://doi.org/10.4103/22308210.104154)

Jin X, Zhang S, Ding T, Zhao P, Zhang C, Zhang Y \& Li W 2020 Testicular Lmcd1 regulates phagocytosis by Sertoli cells through modulation of NFAT1/Txlna signaling pathway. Aging Cell 19 e13217. (https://doi.org/10.1111/acel.13217)

Jungmann RA, Huang D \& Tian D 1998 Regulation of LDH-A gene expression by transcriptional and posttranscriptional signal transduction mechanisms. Journal of Experimental Zoology 282 188-195. (https://doi.org/10.1002/(SICI)1097010X(199809/10)282:1/2<188::AID-JEZ21>3.0.CO;2-P)

Jurek S, Sandhu MA, Trappe S, Bermudez-Pena MC, Kolisek M, Sponder G \& Aschenbach JR 2020 Optimizing adipogenic transdifferentiation of bovine mesenchymal stem cells: a prominent role of ascorbic acid in FABP4 induction. Adipocyte 9 35-50. (https:// doi.org/10.1080/21623945.2020.1720480)

Li W, Wu ZQ, Zhao J, Guo SJ, Li Z, Feng X, Ma L, Zhang JS, Liu XP \& Zhang YQ 2011 Transient protection from heat-stress induced apoptotic stimulation by metastasis-associated protein 1 in pachytene spermatocytes. PLoS ONE 6 e26013 (https://doi. org/10.1371/journal.pone.0026013)

Li W, Fu J, Zhang S, Zhao J, Xie N \& Cai G 2015 The proteasome inhibitor bortezomib induces testicular toxicity by upregulation of oxidative stress, AMP-activated protein kinase (AMPK) activation and deregulation of germ cell development in adult murine testis. Toxicology and Applied Pharmacology 285 98-109. (https://doi. org/10.1016/j.taap.2015.04.001)

Liang WJ, Johnson D \& Jarvis SM 2001 Vitamin C transport systems of mammalian cells. Molecular Membrane Biology 18 87-95. (https://doi. org/10.1080/09687680110033774)

Loboda A, Jozkowicz A \& Dulak J 2012 HIF-1 versus HIF-2 - is one more important than the other? Vascular Pharmacology 56 245-251. (https://doi.org/10.1016/j.vph.2012.02.006)

Luo Y, Mohsin A, Xu C, Wang Q, Hang H, Zhuang Y, Chu J \& Guo M 2018 Co-culture with TM4 cells enhances the proliferation and migration of rat adipose-derived mesenchymal stem cells with high stemness. Cytotechnology 70 1409-1422. (https://doi.org/10.1007/ s10616-018-0235-3)

Ma L, Li W, Zhu HP, Li Z, Sun ZJ, Liu XP, Zhao J, Zhang JS \& Zhang YQ 2010 Localization and androgen regulation of metastasis-associated protein 1 in mouse epididymis. PLOS ONE 5 e15439. (https://doi. org/10.1371/journal.pone.0015439)

Nualart F, Mack L, Garcia A, Cisternas P, Bongarzone ER, Heitzer M, Jara N, Martinez F, Ferrada L, Espinoza F, et al. 2014 Vitamin C transporters, recycling and the bystander effect in the nervous system: SVCT2 versus gluts. Journal of Stem Cell Research and Therapy 4 209. (https://doi.org/10.4172/2157-7633.1000209)

Rato L, Alves MG, Socorro S, Duarte AI, Cavaco JE \& Oliveira PF 2012 Metabolic regulation is important for spermatogenesis. Nature Reviews: Urology 9 330-338. (https://doi.org/10.1038/ nrurol.2012.77)

Regueira M, Riera MF, Galardo MN, Camberos Mdel Mdel C, Pellizzari EH, Cigorraga SB \& Meroni SB 2015 FSH and bFGF regulate the expression of genes involved in Sertoli cell energetic metabolism. General and Comparative Endocrinology 222 124-133. (https://doi. org/10.1016/j.ygcen.2015.08.011)

Rossi SP, Windschuttl S, Matzkin ME, Rey-Ares V, Terradas C, Ponzio R, Puigdomenech E, Levalle O, Calandra RS, Mayerhofer A, et al. 2016 Reactive oxygen species (ROS) production triggered by prostaglandin D2 (PGD2) regulates lactate dehydrogenase (LDH) expression/activity in TM4 Sertoli cells. Molecular and Cellular Endocrinology 434 154-165. (https://doi.org/10.1016/j.mce.2016.06.021)

Salazar K, Martinez M, Ulloa V, Bertinat R, Martinez F, Jara N, Espinoza F, Bongarzone ER \& Nualart F 2016 SVCT2 overexpression in neuroblastoma cells induces cellular branching that is associated with ERK signaling. Molecular Neurobiology 53 6668-6679. (https:// doi.org/10.1007/s12035-015-9553-z)

Schrade A, Kyronlahti A, Akinrinade O, Pihlajoki M, Fischer S, Rodriguez VM, Otte K, Velagapudi V, Toppari J, Wilson DB, et al. 2016 GATA4 regulates blood-testis barrier function and lactate metabolism in mouse Sertoli cells. Endocrinology 157 2416-2431. (https://doi.org/10.1210/en.2015-1927)

Semenza GL 2010 HIF-1: upstream and downstream of cancer metabolism. Current Opinion in Genetics and Development 20 51-56. (https://doi.org/10.1016/j.gde.2009.10.009)

Shen L, Tang X, Wei Y, Long C, Tan B, Wu S, Sun M, Zhou Y, Cao X \& Wei G 2018 Vitamin E and vitamin C attenuate Di-(2-ethylhexyl) phthalate-induced blood-testis barrier disruption by p38 MAPK in immature SD rats. Reproductive Toxicology 81 17-27. (https://doi org/10.1016/j.reprotox.2018.06.015)

Sun J, Yin B, Tang S, Zhang X, Xu J \& Bao E 2019 Vitamin C mitigates heat damage by reducing oxidative stress, inducing HSP expression in TM4 Sertoli cells. Molecular Reproduction and Development $\mathbf{8 6}$ 673-685. (https://doi.org/10.1002/mrd.23146) 
Uriostegui-Acosta M, Tello-Mora P, Solis-Heredia MJ, Ortega-Olvera JM, Pina-Guzman B, Martin-Tapia D, Gonzalez-Mariscal L \& QuintanillaVega B 2020 Methyl parathion causes genetic damage in sperm and disrupts the permeability of the blood-testis barrier by an oxidant mechanism in mice. Toxicology 438 152463. (https://doi. org/10.1016/j.tox.2020.152463)

Wu CY, Zhang B, Kim H, Anderson SK, Miller JS \& Cichocki F 2020 Ascorbic acid promotes KIR demethylation during early NK cell differentiation. Journal of Immunology 205 1513-1523. (https://doi. org/10.4049/jimmunol.2000212)

Xiao X, Mruk DD, Lee WM \& Cheng CY 2011 c-yes regulates cell adhesion at the blood-testis barrier and the apical ectoplasmic specialization in the seminiferous epithelium of rat testes. International Journal of Biochemistry and Cell Biology 43 651-665. (https://doi.org/10.1016/j.biocel.2011.01.008)

Xing W, Pourteymoor S \& Mohan S 2011 Ascorbic acid regulates osterix expression in osteoblasts by activation of prolyl hydroxylase and ubiquitination-mediated proteosomal degradation pathway. Physiological Genomics 43 749-757. (https://doi.org/10.1152/ physiolgenomics.00229.2010)

Yan Q, Bartz S, Mao M, Li L \& Kaelin WG, Jr 2007 The hypoxiainducible factor 2alpha $\mathrm{N}$-terminal and $\mathrm{C}$-terminal transactivation domains cooperate to promote renal tumorigenesis in vivo. Molecular and Cellular Biology 27 2092-2102. (https://doi.org/10.1128/ MCB.01514-06)

Yang Y, Wang T, Zhang S, Jia S, Chen H, Duan Y, Wang S, Chen G \& Tian W 2020 Vitamin C alleviates the senescence of periodontal ligament stem cells through inhibition of Notch3 during long-term culture. Journal of Cellular Physiology 236 1237-1251. (https://doi. org/10.1002/jcp.29930)

Zhang S, Li W, Zhu C, Wang X, Li Z, Zhang J, Zhao J, Hu J, Li T \& Zhang Y 2012 Sertoli cell-specific expression of metastasis-associated protein 2 (MTA2) is required for transcriptional regulation of the follicle-stimulating hormone receptor (FSHR) gene during spermatogenesis. Journal of Biological Chemistry $28740471-40483$. (https://doi.org/10.1074/jbc.M112.383802)

Zhang LL, Ma J, Yang B, Zhao J, Yan BY, Zhang YQ \& Li W 2018 Interference with lactate metabolism by mmu-miR-320-3p via negatively regulating GLUT3 signaling in mouse Sertoli cells. Cell Death and Disease 9 964. (https://doi.org/10.1038/s41419-018-0958-2)

Zhao Y, Hou WG, Zhu HP, Zhao J, Wang RA, Xu RJ \& Zhang YQ 2008 Expression of thyrotropin-releasing hormone receptors in rat testis and their role in isolated Leydig cells. Cell and Tissue Research 334 283-294. (https://doi.org/10.1007/s00441-008-0680-y)

Received in final form 28 October 2020

Accepted 16 December 2020

Accepted Manuscript published online 23 December 2020
(C) 2021 Society for Endocrinology Published by Bioscientifica Ltd. Printed in Great Britain 